\title{
$\mathrm{KCS}$ 선형의 4자유도 조종성능 추정
}

김연규 ${ }^{\dagger} \cdot$ · 여동진 $\cdot$ 손남선 $\cdot$ 김선영 $\cdot$ 윤근항 $\cdot$ 오병익

한국해양연구원 해양시스템안전연구소

\section{Prediction of Maneuverability of KCS with 4 Degrees of Freedom}

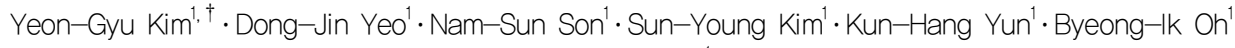

KORDI Maritime \& Ocean Engineering Research Institute

\begin{abstract}
This paper presents the results of prediction of maneuverability of KCS about 4 degree of freedom(DOF) including roll motion. The prediction is carried out by CPMC captive model test. The CPMC(Computerized Planar Motion Carriage) with captive model test equipment including roll moment gage is installed at Ocean Engineering Tank of MOERI. KCS is the container ship open to the world by MOERI. To predict the 4 DOF maneuverability of a ship some tests with roll angle are conducted. And the prediction results of maneuverability by simulation are compared with the results of free running model test. The simulation results agree well with those of free running model tests.
\end{abstract}

Keywords : CPMC(CPMC), KCS(KCS), Captive model test of $4 \mathrm{DOF}$ (4자유도 구속모형시험), Prediction of maneuverability(조종성능 추정), Free running model test(자유항주시험)

\section{1. 서 론}

한국해양연구원 해양시스템안전연구소(MOERI)는 VLCC 선형 인 KVCC1과 KUCC2 선박과 컨테이너선인 KCS의 선형자료와 시험결과를 공개한 바 있으며, 이러한 자료를 이용하여 KUCC1, KVCC2 및 KCS 선형에 대한 CFD 워크숍(CFD Workshop TOKYO 2005, 5th Osaka Colloquium)이 개최되어 많은 논문이 발표된 바 있다(Kim, et al., 2005(1)). 또한 KVCC1, KVCC2 및 KCS 선형에 대한 조종성능 추정용 시험결과를 공개하여 발표 하고 토론하는 워크숍(SIMMAN2008)이 개최된 바 있으며, 국내 에서도 KULCC 선형과 KCS 선형에 대한 연구가 많이 수행되었다 (Kim \& Kim, 2001; Kim, et al., 2005(2)).

$\mathrm{CFD}$ 해석결과 이외에도 조종시험에 의한 KUCC 선형과 $\mathrm{KCS}$ 선형에 대한 연구는 많이 수행되고 있으며, 특히 해양공학수조에 서의 구속모형시험에 의하여 조종성능을 추정하는 시험이 수행되 었다(Shin, et al., 2009; Kim, et al., 2009).

본 논문에서는, $\mathrm{KCS}$ 선형에 대하여 MOERI의 해양공학수조에 설치되어 있는 대형제어형 예인전차 CPMC(Computerized Planar Motion Carriage)를 이용하여 수행된 구속모형시험결과를 이용하 여 조종운동을 시뮬레이션한 결과를 정리하였다. 본 저자의 이전 논문에서는 횡동요가 없는 3 자유도에 대한 시뮬레이션 결과를 일본의 NMRI(National Maritime Research Institute)에서 수행 한 CPMC 구속모형시험결과를 이용하여 추정한 조종성능결과와
독일의 SVA(Schiffbau-Versuchsanstalt Potsdam Gmbh)와 불 가리아의 BSHC(Bulgarian Ship Hydrodynamic Centre)에서 수행한 자유항주시험결과와 비교하였다(Kim, et al., 2009). 하 지만 본 논문에서는 횡메타센터 높이 $\left(G M_{T}\right)$ 가 작은 컨테이너선 에서 크게 발생하는 횡동요 운동을 포함하여 조종운동을 시뮬레 이션하였다. 이러한 횡동요 운동은 선박의 조종성능에 많은 영향 을 미치는 것으로 알려져 있다(Kim, et al., 2003). 횡동요가 포 함된 조종성능 추정을 위하여 구속모형시험에서 횡동요 모멘트 를 계측하였고, 횡경사각이 있는 상태에 대한 구속모형시험을 수 행하였다. 구속모형시험은 모형선에 선체길이 $(\mathrm{x})$ 방향으로 힘이 작용하지 않는 모형선 자항점에서 수행되었으며, 조종성능 추정 결과는 3자유도 추정결과와 MOERI에서 수행된 자유항주시험결 과와 비교하였다.

\section{2. 모형선 및 구속모형시험장치}

KCS 선형의 제원은 Table 1에 정리되어 있다. 시험속도는 실선의 $24.0 \mathrm{Kts}$ 에 해당하는 $1.522 \mathrm{~m} / \mathrm{s}$ 에 대해서 수행되었다. Fig. 1에는 시험에 사용된 모형선의 사진이 나타나 있다.

$\mathrm{CPMC}$ 구속모형시험장치에 대한 자세한 내용은 $\mathrm{Kim}$, et al.(2006)에 나타나 있으며, Fig. 2에는 구속모형시험장치의 사 진이 나타나 있다. 
Table 1 Principal dimensions of KCS

\begin{tabular}{c|c|c}
\hline Dimensions & Real Ship & Model Ship \\
\hline Scale Ratio & 1.0 & 65.833 \\
\hline Lpp $(\mathrm{m})$ & 230.0 & 3.4937 \\
\hline B $(\mathrm{m})$ & 32.2 & 0.4891 \\
\hline$D(\mathrm{~m})$ & 19.0 & 0.2886 \\
\hline$T(\mathrm{~m})$ & 10.8 & 0.1641 \\
\hline Displace. $\left(\mathrm{m}^{3}\right)$ & 52030 & 0.1824 \\
\hline AT $\left(\mathrm{m}^{2}\right)$ & 54.45 & 0.01256 \\
\hline DP $(\mathrm{m})$ & 7.9 & 0.12 \\
\hline P/DP $(0.7 R)$ & 0.8 & 0.8 \\
\hline KG $(\mathrm{m})$ & 14.34 & 0.2178 \\
\hline GMT $(\mathrm{m})$ & 0.60 & 0.00918 \\
\hline$U(\mathrm{~m} / \mathrm{s})$ & $24.0 \mathrm{Kts}$ & 1.522 \\
\hline
\end{tabular}

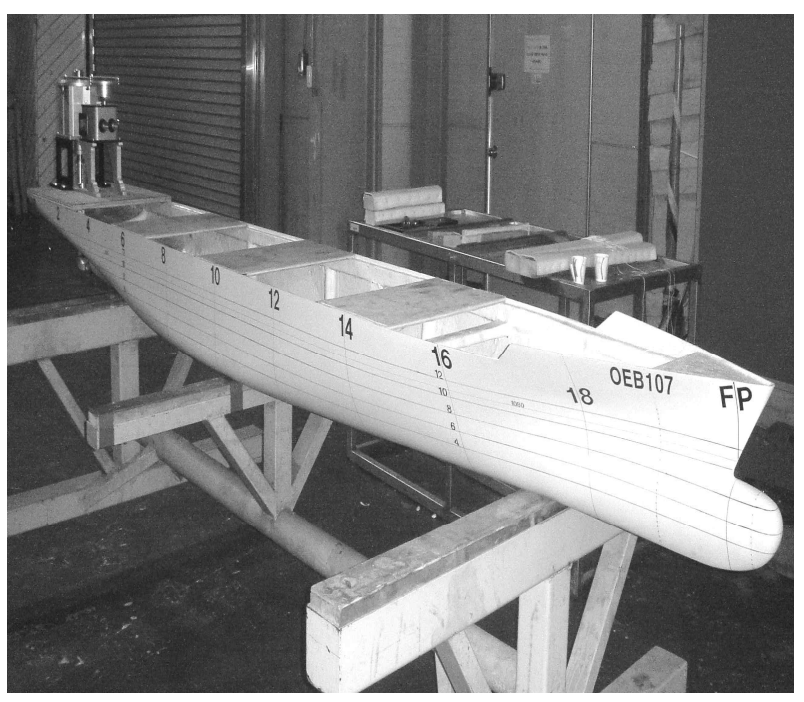

Fig. 1 Model ship of MOERI

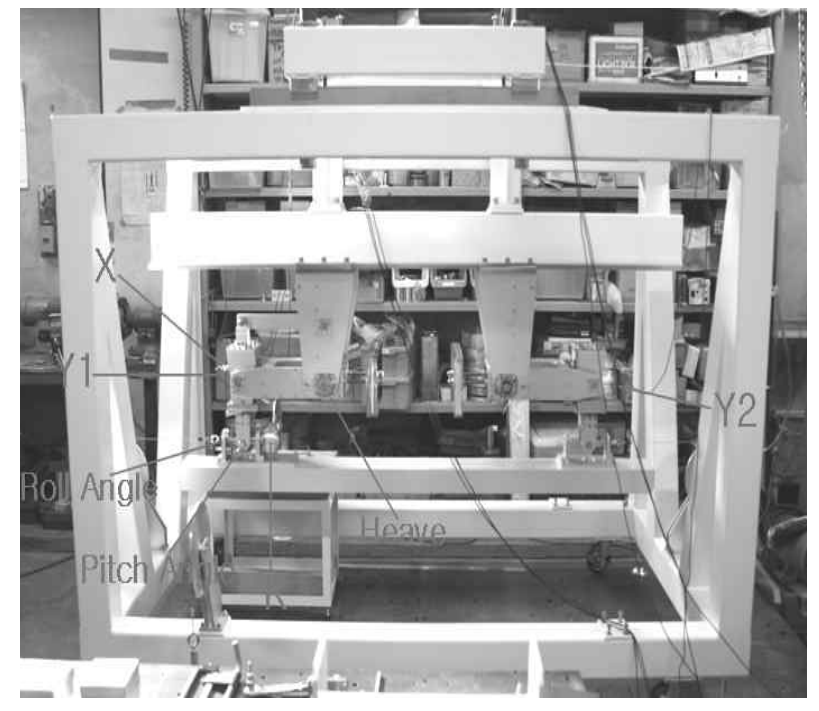

Fig. 2 Captive model test equipment

\section{3. 구속모형시험 및 해석결과}

\section{1 수학모형(Kim, et al. 2007)}

선체 고정 좌표에서의 횡동요를 포함한 4자유도 연성 운동방 정식은 Fig. 3 의 좌표계 하에서 다음과 같다.
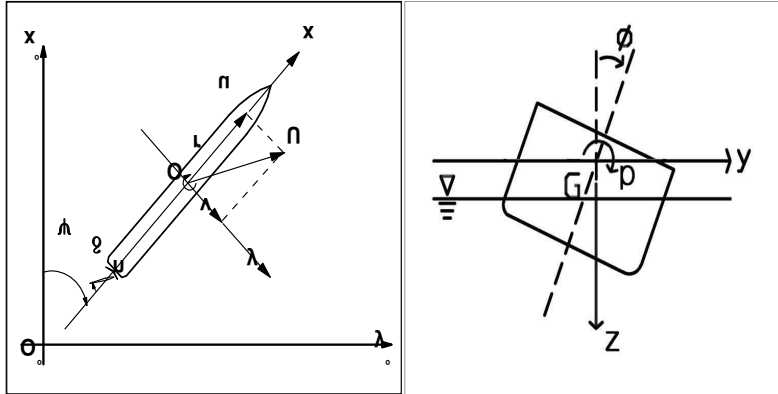

Fig. 3 Coordinates system

$$
\begin{aligned}
m\left(\dot{u}-r v-x_{G} r^{2}+z_{G} p r\right) & =X_{H}+X_{P}+X_{R} \\
m\left(\dot{v}+r u-z_{G} \dot{p}+x_{G} \dot{r}\right) & =Y_{H}+Y_{P}+Y_{R} \\
I_{X X} \dot{p}-m z_{G}(\dot{v}+r u) & =K_{H}+K_{P}+K_{R} \\
I_{Z Z} \dot{r}+m x_{G}(\dot{v}+r u) & =N_{H}+N_{P}+N_{R}
\end{aligned}
$$

식 (1)에서 아래첨자 $H, P, R$ 은 각각 선체, 프로펠러, 타 에 의한 유체력을 나타내고, 위 첨자 - 와 아래첨자 $G$ 는 각기 시간에 대한 미분과 무게중심의 위치를 의미하며, $u, v, r, p$ 는 각각 전진방향, 횡방향, 선수요방향, 횡동요방향 속도를 나 타낸다.

\subsection{1 선체에 작용하는 힘과 모멘트}

$$
\begin{aligned}
X_{H}= & X_{\dot{u}} \dot{u}+X_{v r} v r+X(u)+X_{v v} v^{2}+X_{r r} r^{2} \\
Y_{H}= & Y_{\dot{v}} \dot{v}+Y_{\dot{r}} \dot{r}++Y_{v} v+Y_{r} r+Y_{\phi} \phi \\
& +Y_{v|v|} v|v|+Y_{r|r|}|r|+Y_{\phi|\phi|} \phi|\phi|+Y_{v r r} v r r \\
& +Y_{v v r} v v r+Y_{v|\phi|} v|\phi|+Y_{r|\phi|} r|\phi|+Y_{\phi v v} \phi v v+Y_{\phi r r} \phi r r \\
K_{H}= & K_{\dot{p}} \dot{p}+K_{\dot{v}} \dot{v}+K_{\dot{r}} \dot{r}+K_{p} p+K_{\phi} \phi-W G M_{T} \phi \\
& +\left(Y_{v} v+Y_{v|v|} v|v|\right)\left(z_{Y}\right)_{v}+\left(Y_{r} r+Y_{r|r|} r|r|\right)\left(z_{Y}\right)_{r} \\
N_{H}= & N_{\dot{v}} \dot{v}+N_{r} \dot{r}+N_{v} v+N_{r} r+N_{\phi} \phi+N_{v|v| v|v|} v \mid \\
& +N_{r|r| r} r|r|+N_{v r r} v r r+N_{v v r} v v r+N_{v|\phi|} v|\phi| \\
& +N_{r|\phi|} r|\phi|+N_{\phi v v} \phi v v+N_{\phi r r} \phi r r
\end{aligned}
$$

$X(u):$ 직진시 선체 저항

$\left(z_{Y}\right)_{v},\left(z_{Y}\right)_{r}$ : 사항 및 선회시 선체에 대한 수평 방향 힘 작용점의 $Z$ 좌표 값

$W$ : 선체 중량 $(m g)$

$G M_{T}:$ 횡메타센타 높이 


\section{1 .2 프로펠러에 의한 유체 동력학적 힘}

$X_{P}=(1-t) T$

$T=\rho n^{2} D_{P}^{4} K_{T}\left(J_{P}\right)$

$J_{P}=\frac{u_{P}}{n D_{P}}$

$u_{P}=\left(1-w_{P}\right) U$

$w_{P}=w_{P 0} \exp \left(-C_{P} v_{P}^{2}\right)$

$v_{P}=v+x_{P} r$

$t:$ 추력감소계수

$x_{P}$ : 프로펠러 위치의 $x$ 좌표

\subsection{3 타에 의한 유체력}

$X_{R}=-\left(1-t_{R}\right) F_{N} \sin \delta$

$Y_{R}=\left(1+a_{H}\right) F_{N} \cos \delta$

$K_{R}=-\left(1+a_{H}\right) z_{R} F_{N} \cos \delta$

$N_{R}=\left(x_{R}+a_{H} x_{H}\right) F_{N} \cos \delta$

$F_{N}=\frac{1}{2} \rho u_{R}^{2} A_{R} f_{\alpha} \sin \alpha_{R}$

$u_{R}=\epsilon u_{p} \sqrt{\left\{\eta 1+\kappa\left(\sqrt{1+\frac{8 K_{T}}{\pi J_{P}^{2}}}-1\right)\right\}^{2}+(1-\eta)}$

$\eta=\frac{D_{P}}{H_{R}}$

$\alpha_{R}=\left(\delta-\delta_{0}\right)-\gamma_{R}\left(v^{\prime}+l_{R} r^{\prime}\right)\left(\frac{U}{u_{R}}\right)$

$l_{R} \approx 2 x_{R}$

$\left(1-t_{R}\right):$ 타에 의하여 생기는 저항감소

$F_{N}:$ 타 직압력

$a_{H}, x_{H}$ : 타에 의하여 선체에 작용하는 간섭효과

$x_{R}:$ 타 위치의 $x$ 좌표

$z_{R}$ : 타의 압력 중심의 $z$ 좌표

$f_{\alpha}:$ 타 직압력 계수

$D_{P}, H_{R}:$ 프로펠러 직경과 타의 높이

\section{2 구속모형시험}

$\mathrm{KCS}$ 선형에 대한 구속모형 시험조건은 Table 2에 정리되어 있다. 3자유도 조종성능 해석을 위한 시험이외에 횡동요 운동을 포함한 해석을 위하여 별도의 시험이 수행되었다. 3자유도 구속 모형시험에서도 횡동요 모멘트를 계측하여 횡동요 운동 해석에 사용하였다. Fig. 4에는 구속모형시험 중인 사진이 나타나 있다.
시험은 $1.522 \mathrm{~m} / \mathrm{s}$ 에서 수행되었으며, 모형선 자항점에 해당하는 프로펠러 rps는 15.8 이었다. 그리고 부가질량계수를 구하기 위하 여 동적시험이 수행되었다.

Table 2 Test conditions

\begin{tabular}{|c|c|}
\hline Test Item & Test Condition \\
\hline Resistance & $U=0.5,0.7,0.9,1.1,1.3,1.5,1.522,1.6 \mathrm{~m} / \mathrm{sec}$ \\
\hline $\begin{array}{c}\text { Self } \\
\text { Propulsion }\end{array}$ & $\mathrm{rps}=15.0,13.0,17.0,16.0,15.8$ \\
\hline $\begin{array}{l}\text { Static } \\
\text { Rudder }\end{array}$ & $\delta=0^{o}, \pm 5^{\circ}, \pm 10^{\circ}, \pm 15^{o}, \pm 20^{\circ}, \pm 30^{\circ}$ \\
\hline $\begin{array}{l}\text { Rudder \& } \\
\text { Drift \& } \\
\text { Turning }\end{array}$ & $\begin{array}{c}\beta=0^{o}, \pm 3^{\circ}, \pm 6^{o}, \pm 10^{\circ}, \pm 15^{\circ}, \pm 20^{\circ} \\
r^{\prime}= \pm 0.15, \pm 0.3, \pm 0.5 \\
\delta: 3 \sim 4 \text { Rudder Angles }\end{array}$ \\
\hline Static Drift & $\beta=0^{o}, \pm 2^{o}, \pm 4^{o}, \pm 6^{o}, \pm 8^{o}, \pm 12^{o}, \pm 16^{o}, \pm 20^{o}$ \\
\hline Turning & $r^{\prime}= \pm 0.15, \pm 0.2, \pm 0.3, \pm 0.4, \pm 0.5, \pm 0.6, \pm 0.7$ \\
\hline $\begin{array}{l}\text { Drift \& } \\
\text { Turning }\end{array}$ & $\begin{array}{c}\beta=4^{o}, 8^{\circ}, 12^{\circ}, 16^{o} \\
r^{\prime}= \pm 0.2, \pm 0.4, \pm 0.6\end{array}$ \\
\hline Pure Sway & $\ddot{v}^{\prime}=-0.08 .-0.12,-0.16$ \\
\hline Pure Yaw & $\dot{r}^{\prime}=-0.12,-0.24,-0.36,-0.48$ \\
\hline Static Heel & $\phi=2.670 .3 .446,-4.075$ \\
\hline Drift \& Heel & $\begin{array}{c}\phi=2.670 .3 .446,-4.075 \\
\beta=0^{\circ}, 4^{o}, 8^{\circ}, 12^{\circ}, 16^{\circ}\end{array}$ \\
\hline $\begin{array}{c}\text { Turning \& } \\
\text { Heel }\end{array}$ & $\begin{array}{c}\phi=2.670 .3 .446,-4.075 \\
r^{\prime}= \pm 0.2, \pm 0.4\end{array}$ \\
\hline $\begin{array}{l}\text { Free Roll } \\
\text { Decay }\end{array}$ & $U=0.0,0.5073,1.0147,1.5220 \mathrm{~m} / \mathrm{sec}$ \\
\hline
\end{tabular}

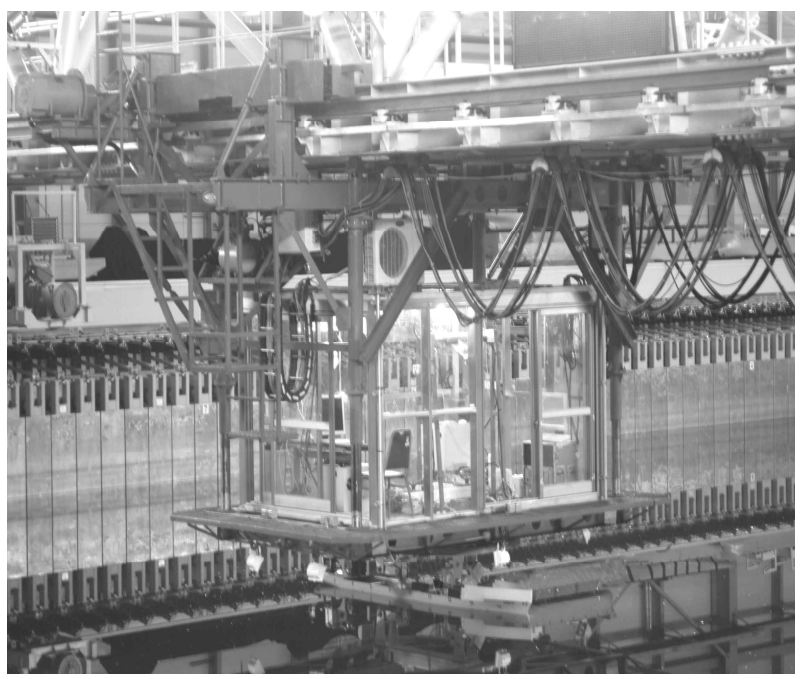

Fig. 4 Photograph of CPMC captive model test 


\section{3 해석결과}

구속모형 시험결과를 수학모형의 조종유체력 계수들을 구하 기 위하여 해석하였다. 계측된 힘과 모멘트는 다음 식과 같이 무차원화하였다.

Forcé $=\frac{\text { Force }}{0.5 \rho U^{2} L^{2}}$, Moment $=\frac{\text { Moment }}{0.5 \rho U^{2} L^{3}}$

Fig. 5에는 타각시험에서 계측된 횡동요 모멘트를 해석한 그 림이 나타나 있고, Fig. 6에는 사항시험에서 계측된 횡동요 모 멘트를 해석한 그림이 나타나 있다. Fig. 5의 결과로부터 $z_{R}$ 이 구해지고, Fig. 6의 결과로부터 $\left(z_{Y}\right)_{v}$ 가 구해진다. Fig. 7에는 선회시험에서 계측된 횡동요 모멘트를 해석한 그림이 나타나 있 고, 이 결과로부터 $\left(z_{Y}\right)_{r}$ 이 구해진다. Fig. 8에는 횡경사시험에 서 계측된 횡동요 모멘트에 대한 해석결과가 실려 있고, Figs. 9 와 10 에 는 횡경사가 있는 상태에 대해서 사항시험과 선회시험 을 수행한 결과가 실려 있다. Fig. 11에는 자유감쇠시험의 시험 결과가 나타나 있다. 자유감쇠시험결과로부터 $K_{p}$ 를 다음과 같 이 구할 수 있다(Beck, et al., 1989).

$K_{p}=\frac{4 k_{d}}{T}\left(I_{x}-K_{\dot{p}}\right)$

이러한 해석에 의하여 구해진 횡동요 운동 관련 조종유체력 계수들이 Table 3에 정리되어 있다. 길이에 대한 무차원화는 $L_{P P}$ 로 하였다. $z_{R},\left(z_{Y}\right)_{v}$ 와 $\left(z_{Y}\right)_{r}$ 을 수면으로부터 흘수에 대 한 거리로 나타내면 0.397T, 0.458T 및 0.115T이다. 이 결과 로부터 선회시험에서는 횡방향 힘의 작용점이 수면 근처에 있 는 것으로 해석되었다. 물론 횡방향 힘뿐만 아니라 상하방향 힘 도 횡동요 모멘트에 영향을 미치므로 복합적으로 검토가 되어 야 한다.

Table 3 Maneuvering coefficients related to roll motion

\begin{tabular}{c|c|c|c}
\hline Coefficients & Value & Coefficients & Value \\
\hline$Y_{\phi}^{\prime}$ & -0.000650 & $N_{\phi}^{\prime}$ & -0.000246 \\
\hline$Y_{v|\phi|}^{\prime}$ & 0.001330 & $N_{v|\phi|}{ }^{\prime}$ & -0.000377 \\
\hline$Y_{\phi v v}^{\prime}$ & -0.15505 & $N_{\phi v v}{ }^{\prime}$ & -0.031590 \\
\hline$Y_{r|\phi|}^{\prime}$ & -0.030511 & $N_{r|\phi|}^{\prime}$ & -0.004124 \\
\hline$Y_{\phi r r}^{\prime}$ & 0.005536 & $N_{\phi r r}{ }^{\prime}$ & -0.000696 \\
\hline$K_{\dot{v}}^{\prime}$ & 0.000061 & $K_{r}^{\prime}$ & 0.0000189 \\
\hline$K_{\phi}^{\prime}$ & -0.000174 & & \\
\hline$\left(z_{Y}\right)_{v}^{\prime}$ & 0.0369 & $\left(z_{Y}\right)_{r}^{\prime}$ & 0.0208 \\
\hline$z_{R}^{\prime}$ & 0.0340 & & \\
\hline
\end{tabular}

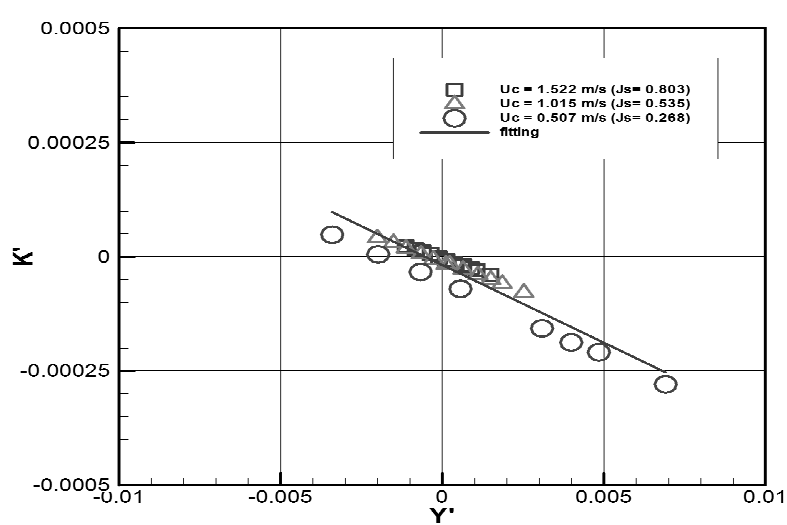

Fig. 5 Analysis of roll moment at static rudder test $(\mathrm{H}+\mathrm{P})$

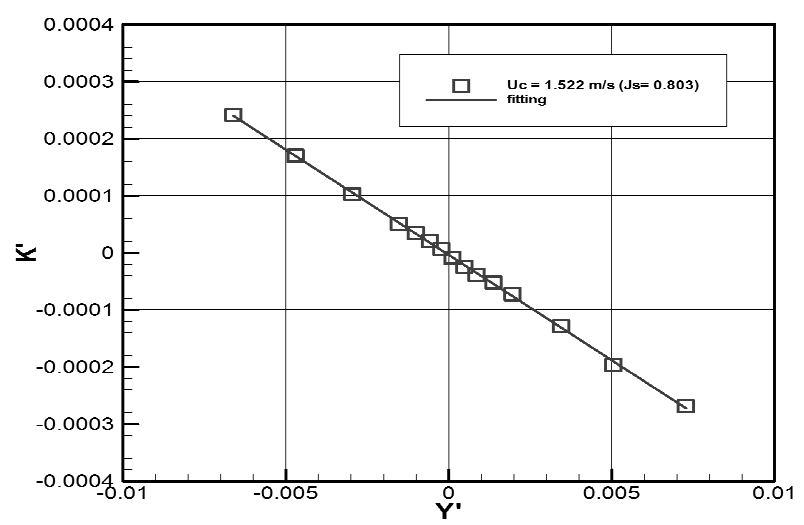

Fig. 6 Analysis of roll moment at static drift test $(\mathrm{H}+\mathrm{P})$

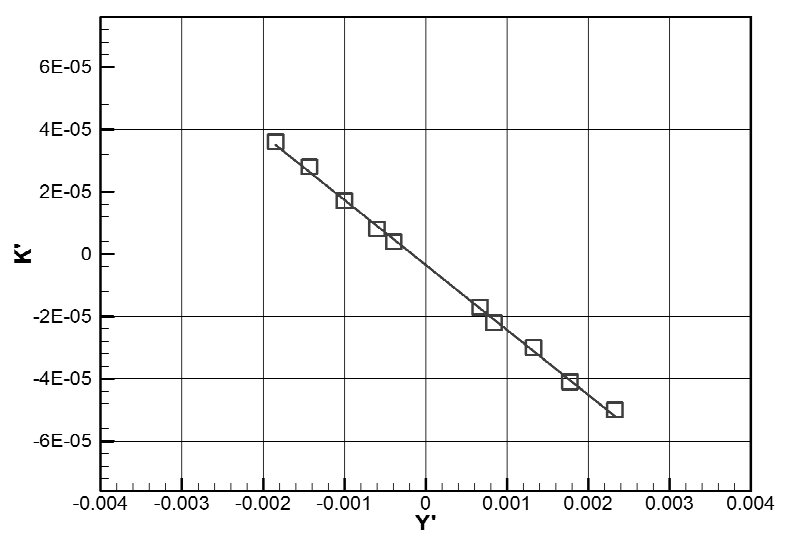

Fig. 7 Analysis of roll moment at turning test $(\mathrm{H}+\mathrm{P})$

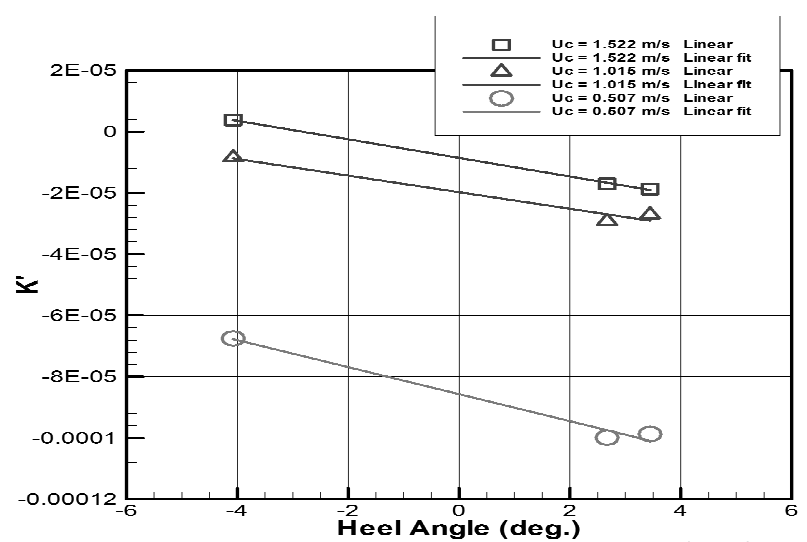

Fig. 8 Analysis of roll moment at static heel test $(\mathrm{H}+\mathrm{P})$ 

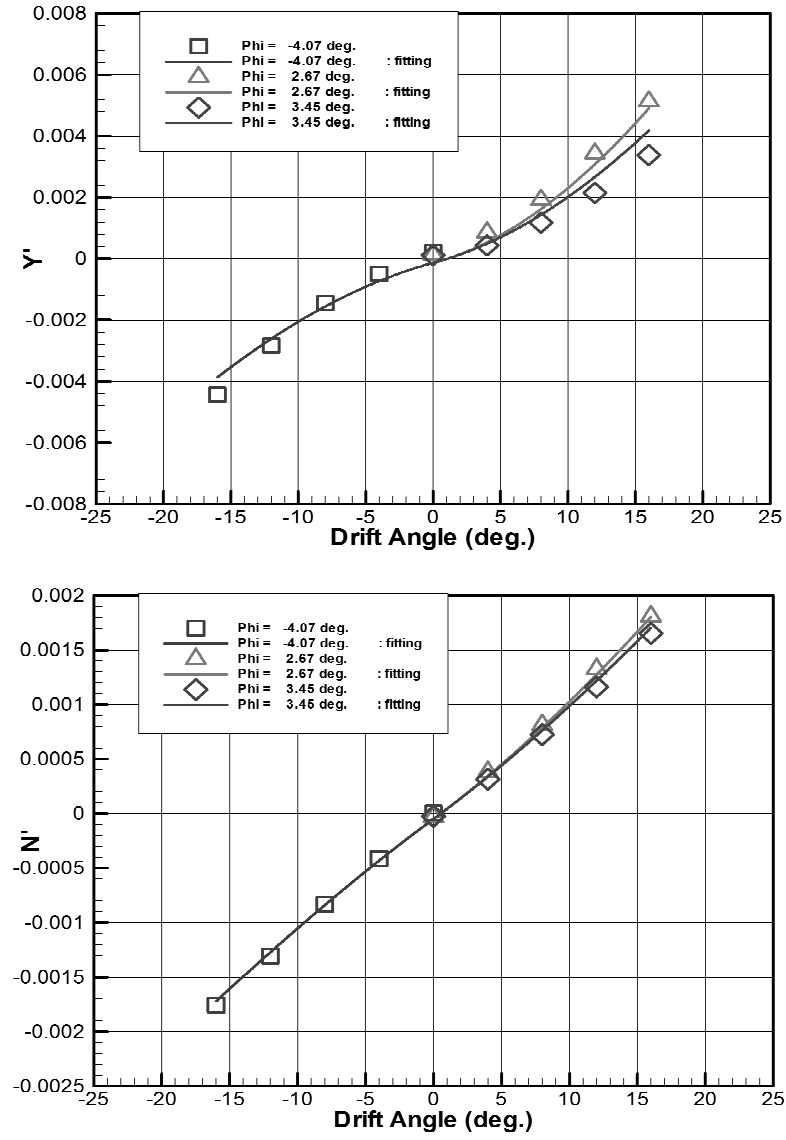

Fig. 9 Analysis of drift with heel test
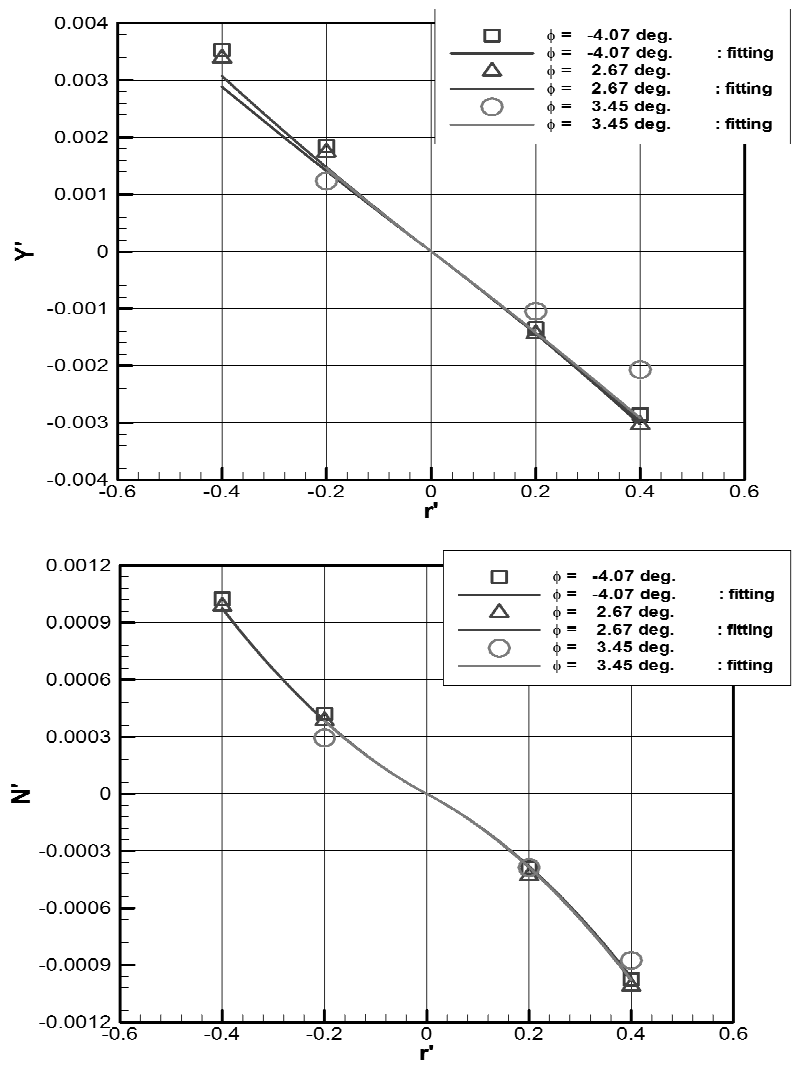

Fig. 10 Analysis of turning with heel test

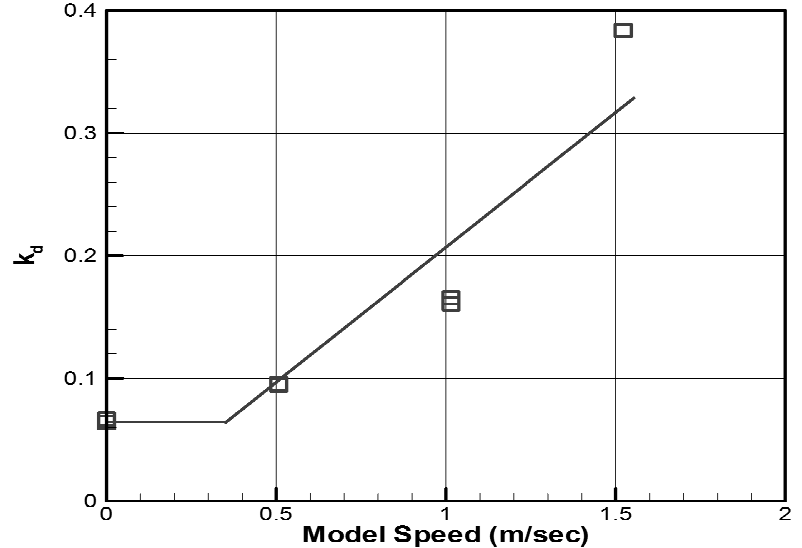

Fig. 11 Analysis of free roll decay test

\section{4. 시뮬레이션 결과}

시험해석에 의하여 구한 조종유체력계수들을 이용하여 KCS 선 형에 대한 4자유도 조종 시뮬레이션을 수행하였다. 단 $K_{\dot{p}}$ 은 경험 식을 사용하였고 $\left(K_{p}^{\prime}=-0.193 I_{x x}{ }^{\prime}\right), Y_{p}$ 와 $N_{p}$ 는 조종운동 중에 는 그 영향이 작다고 판단되어 0 으로 하였다.

Figs. 12 15에는 본 연구에서 수행된 4자유도 시뮬레이션 결 과와 기존의 3 자유도 시뮬레이션 결과 및 자유항주시험결과가 실 려 있다. 자유항주시험은 구속모형시험에 사용된 모형선을 이용 하여 수행되었으며, 모형선 자항점에서 수행되었고, $\mathrm{KG}$ 와 $G M_{T}$ 를 맞추어서 MOERI의 해양공학수조에서 수행되었다. 자유항주시 험시의 모형선 자항점은 $17.8 \mathrm{rps}$ 로서 구속모형시험시의 rps보다 약간 크다. 자유항주시험에 대한 자세한 내용은 Son, et al.(2010) 에 나타나 있다.

Figs. 12 와 13에는 타각 35 도에 대한 우현 및 좌현 선회 시험 결과가 실려 있다. 선회 시험의 경우 4자유도 시뮬레이션 결과가 3자유도 시뮬레이션 결과보다 선회반경이 줄어드는 경향을 보여 주고 있다. 자유항주시험결과는 시뮬레이션 결과보다 작은 선회 반경을 보여주고 있다. 이러한 현상은 모형선 자항점의 rps 차이 에 의한 타 제어력의 차이에 의해서도 발생할 수 있으며, 또한 선 회 초기에서의 선수요 각속도의 크기가 작게 시뮬레이션된 것에 의한 영향에 의해서도 나타날 수도 있다. 시뮬레이션에서 횡동요 운동은 우현 선회의 경우 자유항주시험에서 계측된 횡동요보다 작게 추정되었지만, 좌현 선회에서는 잘 일치하고 있는 것을 볼 수 있다. 이러한 좌우 비대칭 현상 및 선회반경 불일치에 대해서 는 추가적인 연구가 필요하다.

Figs. 14와 15에는 지그재그시험에 대해서 시뮬레이션한 결과 와 자유항주시험 결과가 비교되어 있다. 그림으로부터 4자유도 시뮬레이션 결과는 1st Overshoot Angle이 자유항주시험결과와 잘 일치하는 것을 볼 수 있으며, 3자유도 시뮬레이션보다는 지그 재그성능이 나빠진 것을 알 수 있다. 일반적으로 횡동요 운동이 발생할 경우 선회성능은 좋아지고, 변침성능은 나빠진다고 알려 져 있으며(Kim, et al. 2003), 본 시뮬레이션 결과에서도 그러한 특성이 잘 보이고 있다. 

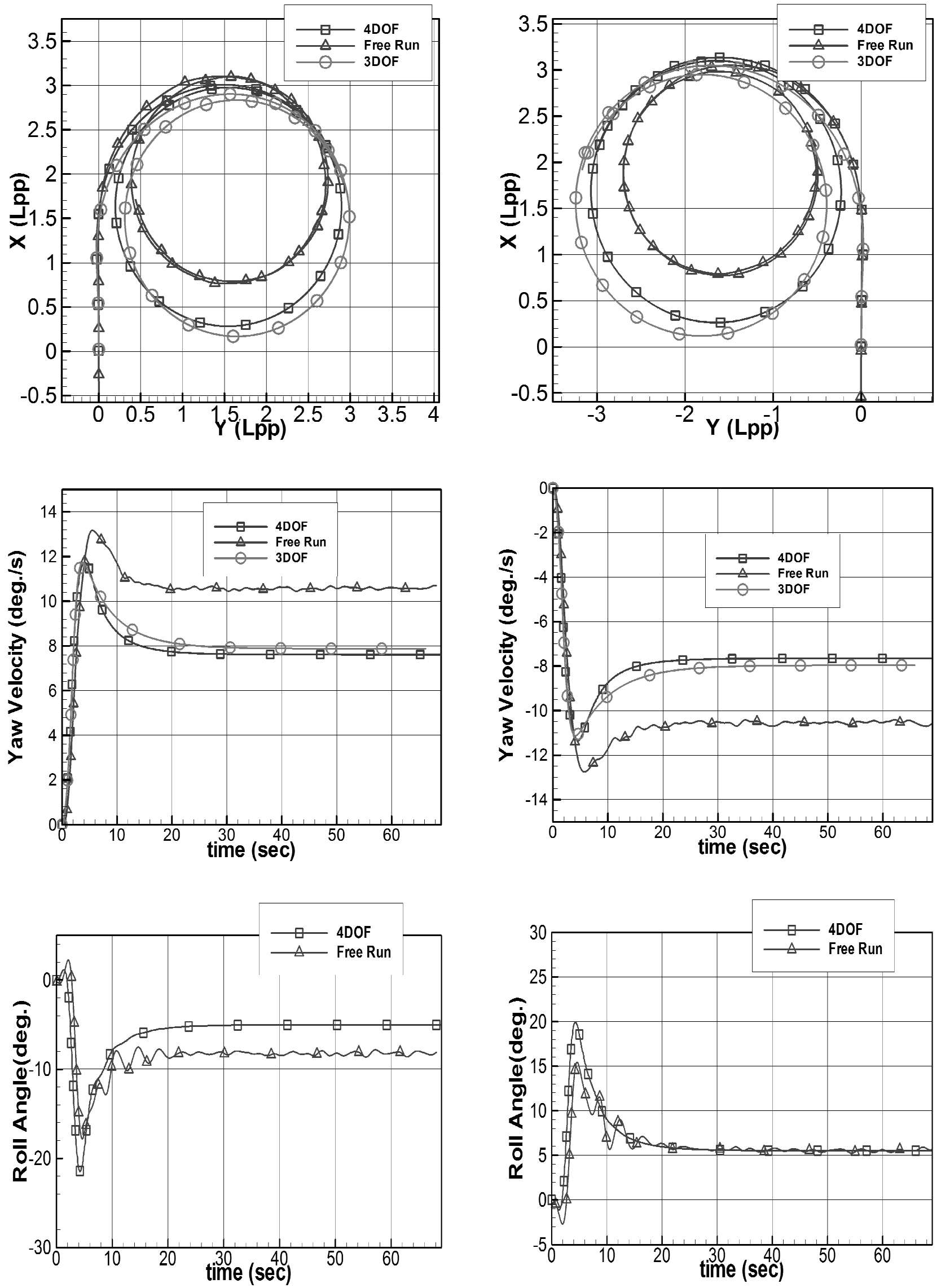

Fig. 12 Simulation results of $35^{\circ}$ starboard rudder turning test

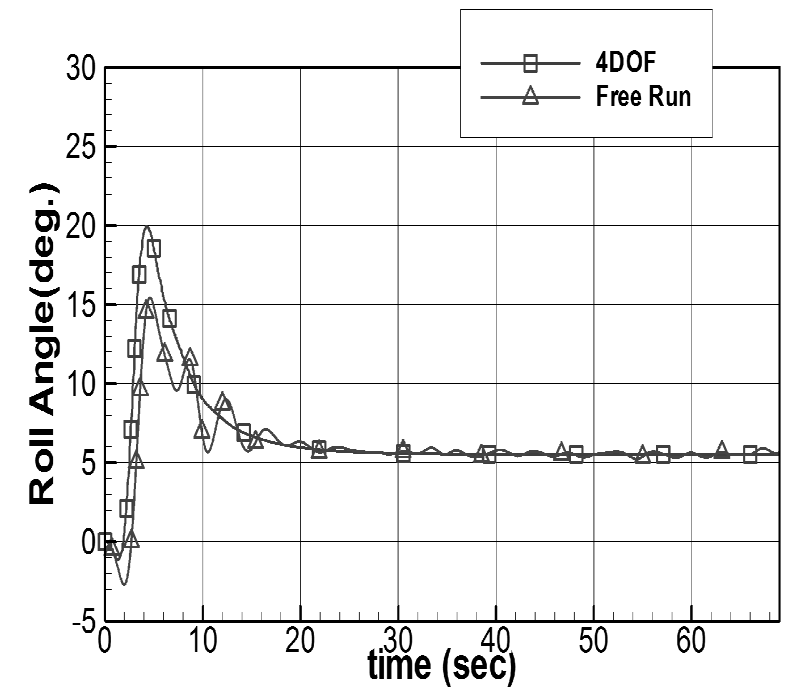

Fig. 13 Simulation results of $35^{\circ}$ port rudder turning test 

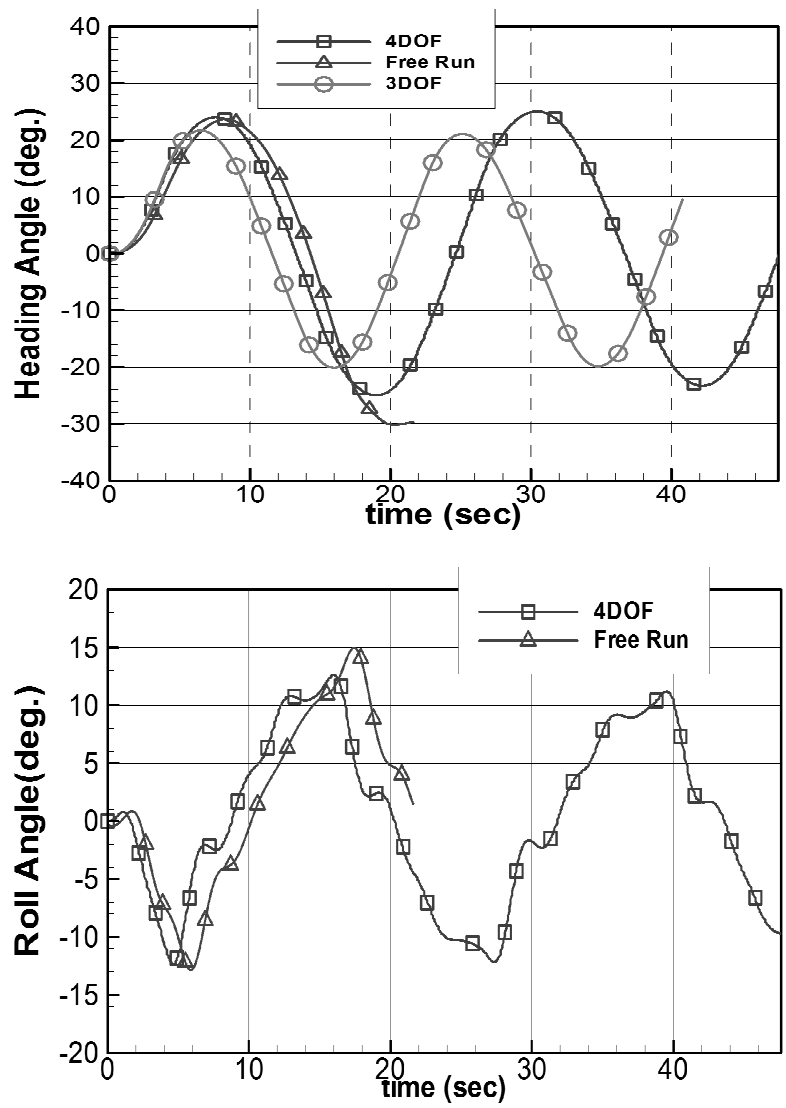

Fig. 14 Simulation results of $10^{\circ} / 10^{\circ}$ zig-zag test
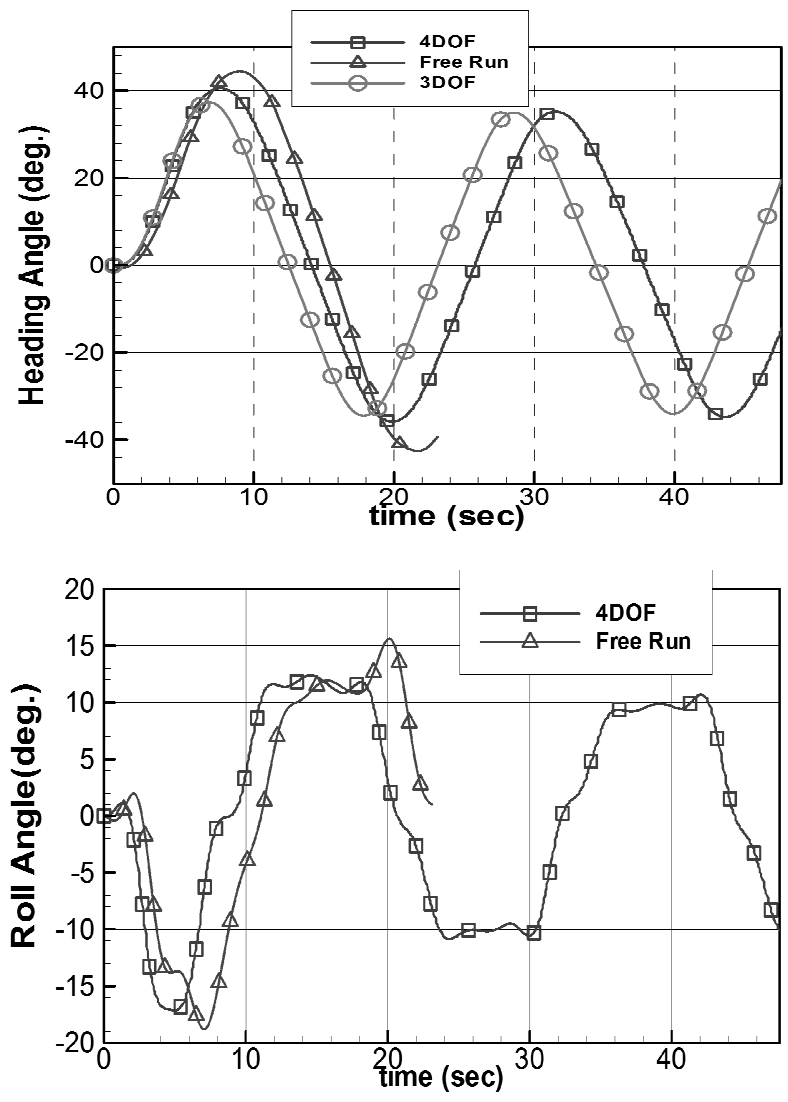

Fig. 15 Simulation results of $20^{\circ} / 20^{\circ}$ zig-zag test
Table 4에는 추정된 조종성능 지수들을 정리하여 나타내었다. 4자유도 조종성능 지수, 3자유도 조종성능 지수가 자유항주시험결 과와 같이 정리되어 있다. 자유항주시험결과는 MOERI에서 수행한 결과와 독일의 SVA(Schiffbau-Versuchsanstalt Potsdam Gmbh) 와 불가리아의 BSHC(Bulgarian Ship Hydrodynamic Centre)에서 수행한 자유항주시험결과(SIMMAN2008)가 실려 있다. SVA와 $\mathrm{BSHC}$ 에서 사용한 모형선의 크기는 $4.37 \mathrm{~m}$ 이었다. 단, 지그재그 시험결과는 좌현과 우현의 결과에 대한 평균값을 정리한 것이 다. 선회시험의 경우 시뮬레이터 결과가 전반적으로 크게 추정 하고 있으며, 지그재그시험의 경우 4자유도 시뮬레이션 결과가 1st Overshoot Angle은 자유항주시험결과와 매우 잘 일치하지만 2nd Overshoot Angle은 작게 추정하고 있다. 이러한 특성으로부 터 선체에 작용하는 비선형 특성이 비교적 크게 나타나는 선회시 험과 2nd Overshoot Angle의 추정에 영향을 주는 비선형계수들 에 대한 검토가 필요하다고 생각된다.

Table 4 Maneuverability indices

\begin{tabular}{|c|c|c|c|c|c|}
\hline & 3DOF & 4DOF & MOERI & SVA & $\mathrm{BSHC}$ \\
\hline $\begin{array}{l}35^{\circ} \text { Turn } \\
\text { Advance } \\
\text { Tac. Dia. }\end{array}$ & $\begin{array}{l}3.01 \mathrm{~L} \\
3.19 \mathrm{~L}\end{array}$ & $\begin{array}{l}3.07 \mathrm{~L} \\
3.00 \mathrm{~L}\end{array}$ & $\begin{array}{l}3.01 \mathrm{~L} \\
2.64 \mathrm{~L}\end{array}$ & - & - \\
\hline $\begin{array}{l}-35^{\circ} \text { Turn } \\
\text { Advance } \\
\text { Tac. Dia. }\end{array}$ & $\begin{array}{l}2.86 \mathrm{~L} \\
2.94 \mathrm{~L}\end{array}$ & $\begin{array}{l}2.93 \mathrm{~L} \\
2.82 \mathrm{~L}\end{array}$ & $\begin{array}{l}3.06 \mathrm{~L} \\
2.65 \mathrm{~L}\end{array}$ & - & $\begin{array}{l}2.78 \mathrm{~L} \\
2.72 \mathrm{~L}\end{array}$ \\
\hline $\begin{array}{c}10^{\circ} / 10^{\circ} \text { ZigZag } \\
\text { 1st OSA } \\
\text { 2nd OSA }\end{array}$ & $\begin{array}{l}11.31^{\circ} \\
10.78^{\circ}\end{array}$ & $\begin{array}{l}13.55^{\circ} \\
15.67^{\circ}\end{array}$ & $\begin{array}{l}12.23^{\circ} \\
22.08^{\circ}\end{array}$ & $\begin{array}{l}11.0^{\circ} \\
18.6^{\circ}\end{array}$ & $\begin{array}{l}10.8^{\circ} \\
21.0^{\circ}\end{array}$ \\
\hline $\begin{array}{c}20^{\circ} / 20^{\circ} \text { ZigZag } \\
\text { 1st OSA } \\
\text { 2nd OSA }\end{array}$ & $\begin{array}{l}16.95^{\circ} \\
14.99^{\circ}\end{array}$ & $\begin{array}{l}20.11^{\circ} \\
15.91^{\circ}\end{array}$ & $\begin{array}{l}23.54^{\circ} \\
24.40^{\circ}\end{array}$ & $\begin{array}{l}17.8^{\circ} \\
19.9^{\circ}\end{array}$ & $\begin{array}{l}19.0^{\circ} \\
22.0^{\circ}\end{array}$ \\
\hline
\end{tabular}

\section{5. 결 론}

한국해양연구원 해양시스템안전연구소(MOERI)에서 공개한 $\mathrm{KCS}$ 선형에 대하여 CPMC 4자유도 구속모형시험을 수행하여 조종성능을 추정하였다. 그리고 그 추정결과를 기존의 3자유도 추정결과, MOERI에서 수행한 자유항주시험결과 및 SVA, BSHC 의 자유항주시험결과와 비교하였다. 추정결과는 잘 일치하는 부 분도 있지만, 서로 약간의 차이를 보여주고 있는 것을 알 수 있 었다.

- 선회성능은 3 자유도 추정보다 4자유도 추정이 자유항주시험결 과에 더 근접하고 있다.

- 변침성능은 자유항주시험결과와 1st Overshoot Angle에서 잘 일치하고 있다.

- 비선형성이 큰 선회시험과 2nd Overshoot Angle의 추정정도를 높이기 위한 노력이 필요하다. 


\section{후 기}

본 논문은 한국해양연구원 해양시스템안전연구소에서 기본과 제로 수행한 "선박의 자유항주 시뮬레이션 및 검증용 계측시스템 개발"과제에 대한 연구결과의 일부이다.

\section{참 고 문 헌}

Beck, R.F. et al., 1989. Principles of Naval Architecture. Vol. III, SNAME, pp.79-83.

Kim, J. Park, I.R. \& Van, S.H., 2005(1). RANS Computations for KRISO Container Ship and VCC Tanker using the WAVIS Code. Proceeding of CFD Workshop Tokyo 2005, pp.542-547.

Kim, J. Park, I.R. Kim, K.S. \& Van, S.H., 2005(2). RANS Simulations for KRISO Container Ship and VLCC Tanker. Journal of the Society of Naval Architects of Korea, 42(6), pp.592-600.

Kim, S.Y. \& Kim, Y.G., 2001. Computation of Viscous Flows around a Ship with a Drift Angle and the Effects of Stern Hull Form on the Hydrodynamic Forces. Journal of the Society of Naval Architects of Korea, 38(3), pp.1-13.

Kim, S.Y. et al., 2003. Maneuvering Characteristics of a Large Container Ship. Proceeding of MARS/M'03, 3, pp.RC-8-1 RC-8-11.

Kim, Y.G. et al., 2006. Captive Model Test Using CPMC. Proceedings of the Annual Spring Meeting of the Society of Naval Architects of Korea, pp.670-676
Kim, Y.G. Kim, S.Y. Yang, Y.H. \& Son, N.S., 2007. 4-DOF Captive Model Test Using CPMC. Proceedings of the Annual Spring Meeting of the Society of Naval Architects of Korea, pp.924-930.

Kim, Y.G. et al., 2009. Prediction of Maneuverability of KCS by CPMC Captive Model Test. Journal of the Society of Naval Architects of Korea, 46(6), pp.553-561.

Shin, H.K. Yoon, J.H. \& Lee, H.Y., 2009. Prediction of Ship Maneuverability by Circular Motion Test. Journal of the Society of Naval Architects of Korea, 46(3), pp.259-267.

Son, N.S. Kim, S.Y. Kim, Y.G. \& Oh, B.E., 2010. On the Propulsion Support System for Free Running Model Test in the Propulsion Point of Real Ship. Proceedings of the Annual Spring Meeting of the Society of Naval Architects of Korea, pp.2035-2043.
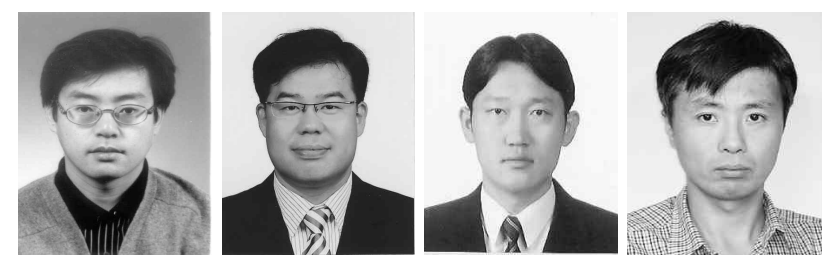

김 연 규

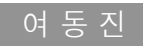

손남 선

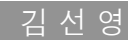

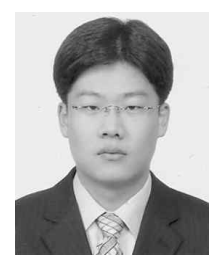

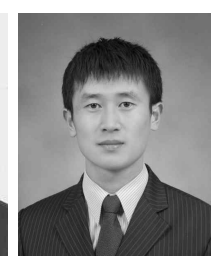

윤 근 항

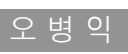

